\title{
Modelling the trajectory of the corpses of mountaineers who disappeared in 1926 on Aletschgletscher, Switzerland
}

\author{
Guillaume JOUVET, ${ }^{1}$ Martin FUNK ${ }^{2}$ \\ ${ }^{1}$ Department of Mathematics and Computer Science, Freie Universität Berlin, Berlin, Germany \\ E-mail: guillaume.jouvet@fu-berlin.de \\ ${ }^{2}$ Laboratory of Hydraulics, Hydrology and Glaciology, ETH Zürich, Zürich, Switzerland
}

\begin{abstract}
In this paper we reconstruct the space-time trajectory beneath the surface of Aletschgletscher, Switzerland, of the corpses of three mountaineers that disappeared in March 1926 and reappeared at the glacier surface in June 2012. Our method integrates the time-dependent velocity field of an existing full-Stokes glacier model, starting at the point where the corpses were found at the glacier surface. Our main result is that we were able to localize the immersion location where the brothers presumably died. As a second result, the upstream end point of the computed trajectory emerges very close to the glacier surface in 1926, giving a new and global validation of the glacier model in space and time. Testing the sensitivity of the immersion location obtained with respect to the model and other uncertainties indicates an area of $0.6 \%$ of the entire glacier area where the accident could have occurred. Our result suggests that death was not caused by an avalanche or a fall into a crevasse; instead, it is likely that the mountaineers became disoriented in prolonged severe weather conditions and froze to death.
\end{abstract}

KEYWORDS: glacier flow, glacier modelling, glaciological model experiments, ice dynamics, mountain glaciers

\section{INTRODUCTION}

Avalanches, crevasses or bad weather conditions have been the cause of many mountaineer fatalities on glaciers in the European Alps over the past two centuries. Since 1992, eight people have disappeared on Swiss glaciers (personal communication from U. Mosimann, Swiss Alpine Club, 2013). Owing to the ice dynamics, their corpses will reappear on the glacier surface at some time in the future. In June 2012, human bones were found at the surface of Aletschgletscher, Switzerland, and were identified as being those of three brothers who went missing in March 1926 (Police Report, 2012: Polizeirapport, Kanton Wallis, unpublished and confidential). Since they were found in the ablation area at $\sim 2400$ ma.s.l., they are likely to have disappeared in the accumulation area, several kilometres upstream. Indeed, any object buried in the accumulation area of a glacier is transported via ice flow along a trajectory and reappears at the surface of the ablation area some time later. In the case of fatally injured people this has been observed several times in the past (Krämer and others, 1988; Ambach and others, 1992; Loreille and others, 2010).

The trajectories of ice particles in a glacier have already been computed by glacier modellers, though not for the same purpose as that of this paper. Most of the time, trajectories are computed in order to date the ice. For instance, a stream-function formulation is added to the iceflow model by Stolle and Killeavy (1986), while a dating advection equation is used by Mügge and others (1999), Durand and others (2007), Zwinger and others (2007) and Martin and others (2009). In a further application, the accumulation of meltwater is computed by integrating strain heating along trajectories starting at the surface in the accumulation area (Aschwanden and Blatter, 2005). The forensic aspects of some cases of corpses released from glaciers were studied by Ambach and others (1992). In that study, the authors give a coarse estimate of the length of the trajectory based on a single assessment of the averaged velocity. To our knowledge, no study has ever applied an entire model to the determination of the trajectory of a set of objects, or corpses, in ice.

The goal of this paper is to reconstruct the trajectory along which the corpses of the brothers who disappeared on Aletschgletscher in 1926 were transported, using the time-dependent reconstructed velocity field of the fullStokes glacier model (Jouvet and others, 2011). By integrating the transient ice velocity field backward-in-time, starting from the location of their reappearance at the glacier surface in 2012, we estimate the location where the three brothers are most likely to have disappeared on the glacier in 1926. This paper is organized as follows. First, we give a short summary of what is known about the disappearance of these three mountaineers. Then we present our method for reconstructing the trajectory from the model data of Jouvet and others (2011). Following that, we present our results, discuss their sensitivity with respect to the sources of error and provide some indications as to what could have happened to the mountaineers in March 1926. Finally, we offer a perspective on potential future applications of our methodology.

\section{HISTORICAL FACTS AND DATA}

Grosser Aletschgletscher is the largest glacier in the European Alps. It consists of three sizeable accumulation basins: Grosser Aletschfirn (West), Jungfraufirn (Nord-West) and Ewigschneefeld (Nord), which merge at Konkordiaplatz (Fig. 1). Downstream of the glacier is a $10 \mathrm{~km}$ long curved tongue. Ever since 1912, when Jungfraujoch became accessible by railway, Aletschgletscher has been an attractive destination for mountaineers (Rossberg, 1983). 
In the early morning of 4 March 1926, three brothers and a fourth person left the village of Kippel, in the Lötschental, to climb to the Hollandiahütte refuge (Fig. 1), and arrived there around noon. At the refuge they talked to a group of tourists and said they planned to go for a hike up to Konkordiaplatz in the afternoon and return to the refuge in the evening. During the afternoon, the weather deteriorated considerably and a heavy snowstorm broke out, which lasted for 3 days. As the group did not return to the valley the next day as expected, a search party set out in the days that followed. Despite many search operations during the next few weeks, no trace of the group was found. It was assumed that they had died somewhere in the vicinity. Seasonal massbalance measurements at Jungfraujoch (located $\sim 5 \mathrm{~km}$ from Hollandiahütte, at 3450 ma.s.l.) confirm heavy snowfalls at the beginning of March (Huss and Bauder, 2009). More importantly, those measurements show that melting during the summer did not remove the snow that fell after 4 March. This means that the bodies were very likely buried immediately and did not reappear after the snowstorm, so it is not surprising they were not found by the search party.

On 27 June 2012, 86 years later, human skeletons (later identified as those of the three brothers) and the remains of old mountaineering equipment were found on Aletschgletscher at the coordinate

$$
\mathbf{x}_{2012}=(648218,146353,2430),
$$

in the Swiss referential (Swiss geodetic datum CH1903), which is $\sim 5 \mathrm{~km}$ downstream of Konkordiaplatz on the glacier tongue (Fig. 1). The fourth group member is still missing.

\section{METHOD}

In this paper, $(x, y)$ denote the horizontal coordinates in the Swiss referential while $z$ marks the vertical coordinate; $b(x, y)$ is the bedrock elevation at point $(x, y), s(x, y, t)$ is the top surface elevation at point $(x, y)$ and time $t$, and $\mathbf{u}(\mathbf{x}, t)$ is the velocity field at point $\mathbf{x}=(x, y, z)$ and time $t$. The trajectory of the particle passing $\overline{\mathbf{x}}$ at time $\bar{t}$ on the time interval $t_{t}$, containing $\bar{t}$, is the set

$$
\left\{\mathbf{x}(t, \overline{\mathbf{x}}, \bar{t}), \quad t \in I_{\bar{t}}\right\},
$$

where $\mathbf{x}(t, \overline{\mathbf{x}}, \bar{t})$ solves the ordinary differential equation:

$$
\left\{\begin{aligned}
\mathbf{x}^{\prime}(t) & =\mathbf{u}(\mathbf{x}(t), t), \quad \text { on } t_{t}^{\prime} \\
\mathbf{x}(\bar{t}) & =\overline{\mathbf{x}}
\end{aligned}\right.
$$

with the symbol ' indicating the time derivative. Given a trajectory $\mathbf{x}(t)=\mathbf{x}(t, \overline{\mathbf{x}}, \bar{t})$, we call the head of the trajectory the pair $\left(\mathbf{x}\left(t^{\mathrm{h}}\right), t^{\mathrm{h}}\right)$, such that

$$
\left\{\begin{aligned}
z\left(t^{\mathrm{h}}\right) & =s\left(x\left(t^{\mathrm{h}}\right), y\left(t^{\mathrm{h}}\right), t^{\mathrm{h}}\right) \\
t^{\mathrm{h}} & =\inf \left\{t \in \mathrm{I}_{\bar{t}}, \quad z(t)<s(x(t), y(t), t)\right\} .
\end{aligned}\right.
$$

By changing 'inf' into 'sup' in the above equation, we define the foot of the trajectory, which is denoted $\left(\mathbf{x}\left(t^{f}\right), t^{f}\right)$. Intuitively, the head, $\left(\mathbf{x}\left(t^{h}\right), t^{h}\right)$, and the foot, $\left(\mathbf{x}\left(t^{f}\right), t^{f}\right)$, of the trajectory correspond to the position and date of the entrance and the exit of the particle in the glacier, respectively. With this notation, our problem takes the following mathematical form: If we know the foot of the trajectory, $\left(\mathbf{x}\left(t^{f}\right), t^{f}\right)$ (corresponding to where and when the skeletons were found), then we want to compute the trajectory $\mathbf{x}(t)=\mathbf{x}(t, \overline{\mathbf{x}}, \bar{t})$ and deduce its head, $\left(\mathbf{x}\left(t^{\mathrm{h}}\right), t^{\mathrm{h}}\right)$ (corresponding to where and when the bodies were buried).
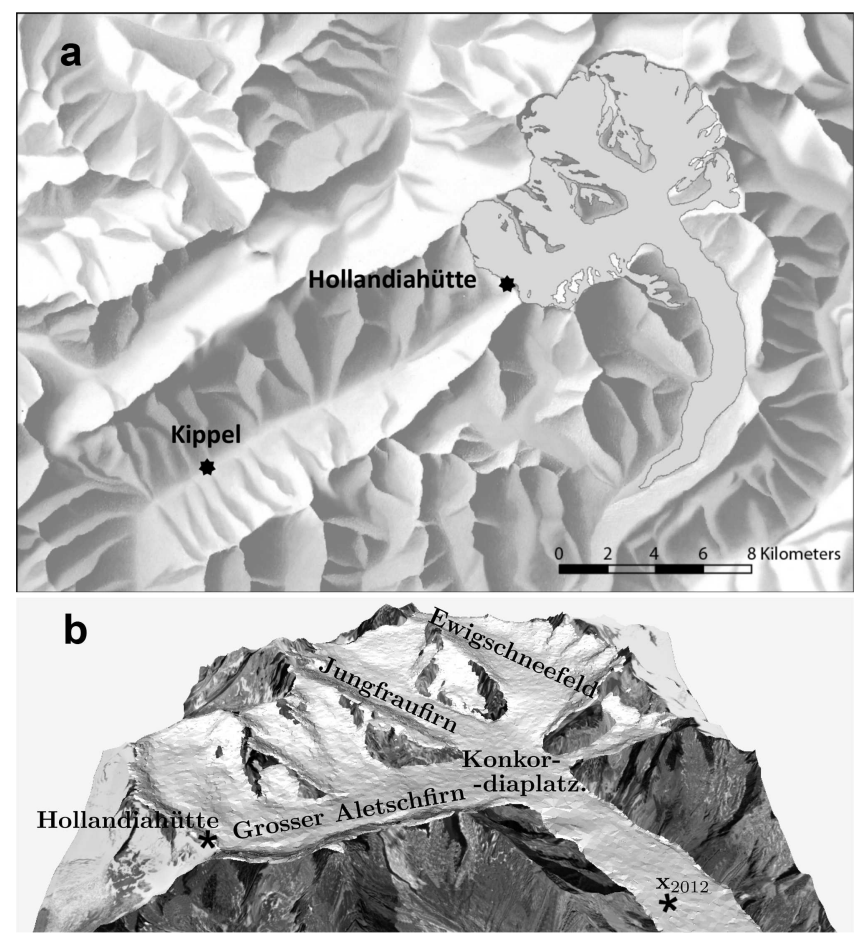

Fig. 1. (a) Map of Grosser Aletschgletscher and the surrounding area. (b) Overview of the uppermost part of Grosser Aletschgletscher. The stars indicate Hollandiahütte on the left, and the location where the skeletons were found on the right.

To compute the trajectory solving Eqn (2), we need the velocity fields over the time period $\left[t^{h}, t^{f}\right]$. For that, we use the results of the model of Aletschgletscher from 1926 to 2012 given by Jouvet and others (2011). For convenience the main features of this model are recalled in the next paragraph.

The motion of ice was described by the nonlinear Stokes equations based on Glen's law. Ice was assumed to be isothermal, as records of englacial temperature show that Grosser Aletschgletscher is mainly temperate. Consequently, the rate factor, $A$, in Glen's law is constant. Sliding of ice over the bedrock below 2400 ma.s.l. was described by a nonlinear Weertman's law with $c$ as a sliding coefficient, with ice assumed to be fixed to the bedrock elsewhere. This is due to the fact that more sliding is expected in the lowest regions of the glacier, where meltwater production increases. Parameters $A=100 \mathrm{MPa}^{-3} \mathrm{a}^{-1}$ and $c=23300 \mathrm{MPa}^{-3} \mathrm{ma}^{-1}$ were found to minimize the discrepancy between modelled and measured surface velocities (Table 2). We calculated the surface mass balance in daily time-steps, using a distributed accumulation and temperature index melt model and climate data. The mass balance was included in the model through a transport equation, which describes the mass conservation. Finally, a decoupling algorithm allowed the Stokes problem and the transport equation to be solved using different numerical methods. First, the nonlinear Stokes equations were solved on a fixed, unstructured mesh consisting of tetrahedrons, using a fixed-point algorithm and the finite-element method. Second, the transport equation was solved on a fixed, structured grid of smaller cells, using the volume-of-fluid method. Further details of the numerical methods are given by Jouvet and others (2008, 2009).

The model proved to be capable of reconstructing Aletschgletscher in the 20th century. Jouvet and others (2011) initialized the model once in 1880 and ran it until 1999. 


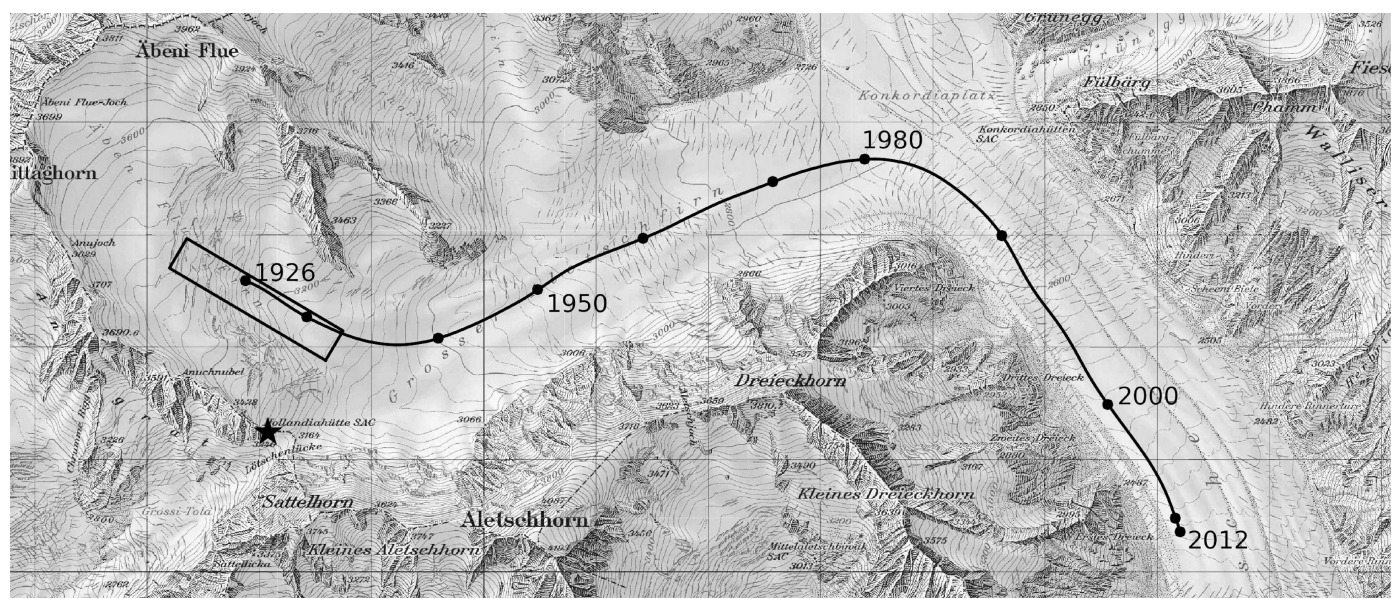

Fig. 2. Aerial view of the modelled trajectory on a topographic map. The black curve represents the trajectory, $\mathbf{x}\left(t, \mathbf{x}_{2012}, 2012\right)$, while the black dots indicate the positions of the trajectory in 1926, 2012 and every decade between 1930 and 2010. The rectangle indicates the confidence of the reconstructed location, $\mathbf{x}\left(1926, \mathbf{x}_{2012}, 2012\right)$, and the star indicates the Hollandiahütte refuge.

Here we use a model for the period 1880-2012, re-initialized in 1926, 1957, 1980 and 1999, years for which digital elevation models (DEMs) are available (Bauder and others, 2007). Such re-initializations prevent cumulative errors from increasing with the length of the modelling period.

Jouvet and others (2011) supply the following approximations: the velocity field, $\mathbf{u}_{a}$, and the upper elevation, $s_{a}$, each half-year, or equivalently for the years, $a$, in $\{1926$, 1926.5, 1927, 1927.5,..,2011.5, 2012\}. Note that the $\mathbf{u}_{a}$ are only available at some nodes of an unstructured mesh of volume $\left\{\mathbf{x}=(x, y, z) \in \mathcal{R}^{3}, \quad b(x, y) \leq z \leq s_{a}(x, y, a)\right\}$, while the $s_{a}$ are available at the centres of the cells of a regular and rectangular horizontal grid. Using $\mathbf{u}_{a}$ instead of $\mathbf{u}, \mathbf{x}_{2012}$ from Eqn (1) instead of $\overline{\mathbf{x}}, 2012$ instead of $\bar{t}$, and $[1926,2012]$ instead of $I_{t}$, we solve the system of Eqn (2), using a fourth-order Runge-Kutta method to obtain an approximation of the trajectory, $\mathbf{x}\left(t, \mathbf{x}_{2012}, 2012\right)$, along which the corpses were transported. Finally, $\mathbf{x}\left(1926, \mathbf{x}_{2012}, 2012\right)$ provides an estimate of the location where the corpses were buried in 1926 .

\section{RESULTS}

Once the trajectory, $\mathbf{x}\left(t, \mathbf{x}_{2012}, 2012\right)$, was computed, we obtained the following point of immersion:

$$
\mathbf{x}_{1926}=\mathbf{x}\left(1926, \mathbf{x}_{2012}, 2012\right)=\left(\begin{array}{l}
639859,148592,3 \\
252
\end{array}\right) \text {. }
$$

The distance from $\mathbf{x}_{1926}$ to the surface in 1926 was

$$
s\left(x_{1926}, y_{1926}, 1926\right)-z_{1926}=3278-3252=26 \mathrm{~m} .
$$

Figure 2 shows an aerial view of the trajectory, $\mathbf{x}\left(t, \mathbf{x}_{2012}\right.$, 2012), on a topographic map from 1926 to 2012. Figure 3a shows the elevation of the trajectory, the bedrock below the trajectory and the surface above the trajectory with respect to time. Figure $3 \mathrm{~b}$ and $\mathrm{c}$ show the velocity, $\mathbf{u}(\mathbf{x}(t), t)$, and the position along the flowline, $\int_{1926}^{t}\|\mathbf{x}(s)\| \mathrm{d} s$, of the particle following the trajectory with respect to time, respectively.

It is remarkable that the elevation of the final upstream position of the trajectory (1926 in Fig. 3a) is only 26 m below the top surface elevation. If the model were free of any numerical and physical errors, then the trajectory would exactly reach the surface in 1926. As a consequence, the observed mismatch of $26 \mathrm{~m}$ is the result of all the approximations in the model. Thus, the depth of $\mathbf{x}_{1926}$ below the top surface is a valuable indicator in assessing the quality of the model. Moreover, this indicator is global, since it accounts for the entire simulation period and a large part of the ice domain. Regarding the accuracy of the numerical model used to solve the Stokes equations by Jouvet and others (2011) (the elements of the mesh are $\sim 30 \mathrm{~m}$ high) and

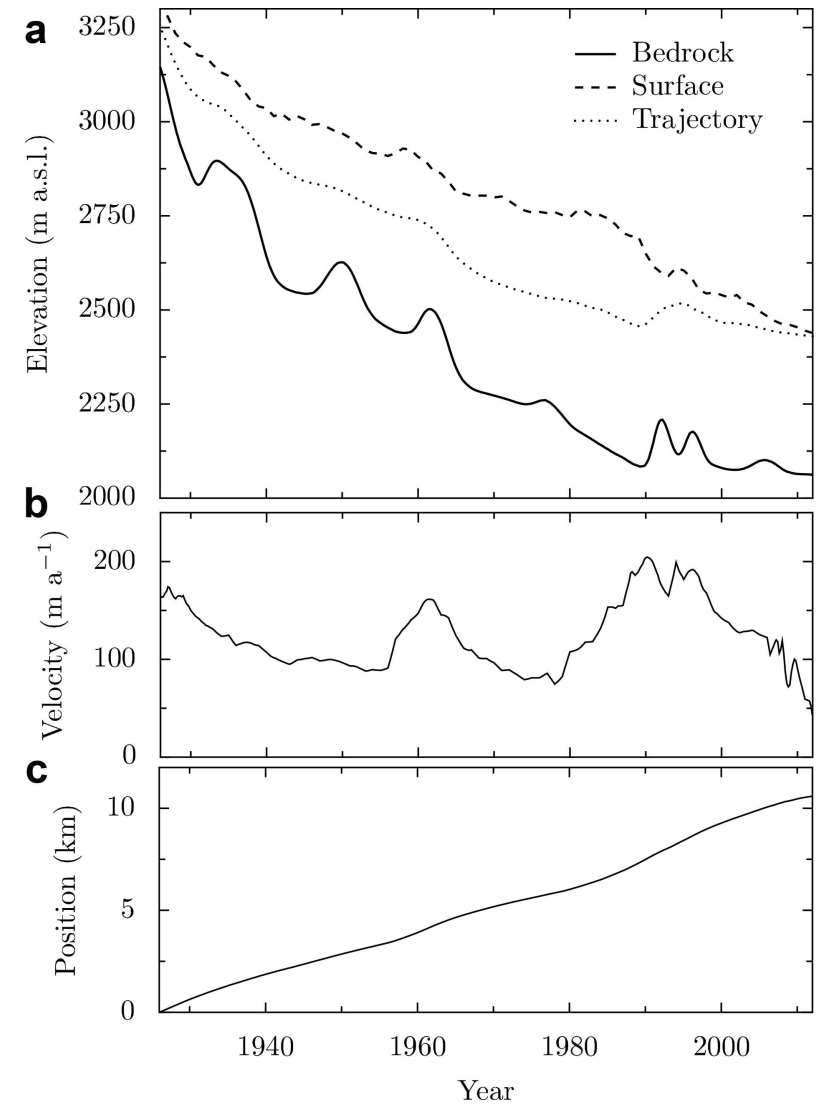

Fig. 3. (a) Elevation of the trajectory $\mathbf{x}(t)=\mathbf{x}\left(t, \mathbf{x}_{2012}, 2012\right)$ (i.e. $z(t)$ ), of the bedrock $b(x(t), y(t))$ and of the upper surface $s(x(t), y(t), t)$ with respect to time, $t$. (b) Velocity across the trajectory, $\mathbf{u}(\mathbf{x}(t), t)$. (c) Position along the flowline, $\int_{1926}^{t}\|\mathbf{x}(s)\| \mathrm{d} s$. 


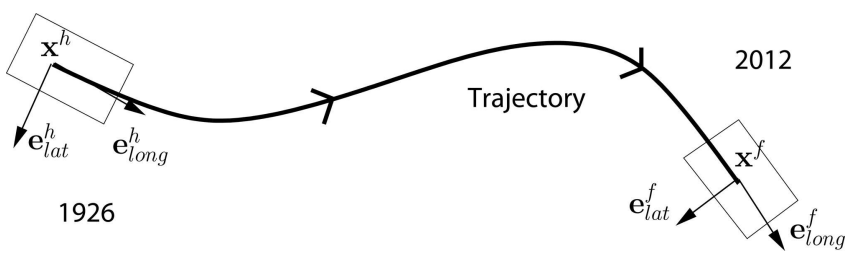

Fig. 4. Definition of the local frames at the upstream and downstream ends of the trajectory.

the accuracy ( \pm 3 to $5 \mathrm{~m}$ ) of the DEM of the surface elevation in 1926 (Bauder and others, 2007), the mismatch can be considered small. That there is only a slight discrepancy further underlines the validity of the model.

According to Figure 3, the corpses were transported $\sim 10.5 \mathrm{~km}$ and lost $\sim 800 \mathrm{~m}$ in altitude from 1926 to 2012 (mean velocity $122 \mathrm{~m} \mathrm{a}^{-1}$ ). As expected, the corpses were regularly advected deeper into the ice until reaching a maximum depth of $\sim 250 \mathrm{~m}$ in 1980, for a total ice thickness of $\sim 600 \mathrm{~m}$ at that location. With such a column of ice cover, the bodies experienced a pressure of $\sim 2 \mathrm{MPa}$, which is corroborated by the deformation observed in the bones that resurfaced in 2012. In 1980, the elevation of the top surface above the bodies was $\sim 2750$ ma.s.I., which is consistent with the equilibrium-line altitudes occurring on Aletschgletscher in the 1980s and 1990s (Huss and others, 2008). After 1980, the path of the corpses was directed mostly towards the glacier surface. According to Figure 2, the trajectory turned to the right at the confluence of Konkordiaplatz from 1980 to 1990, and accelerated at the same time from $\sim 100$ to $200 \mathrm{~m} \mathrm{a}^{-1}$ (Fig. 3).

Our result relies on a number of model approximations, which might contribute to an error in the evaluation of Eqn (3). The sources of error are:

1. error regarding the location of $\mathbf{x}_{2012}$;

2. errors of the surface elevations in 1926 and 2012;

3. mass-balance model errors;

4. ice-flow model errors;

5. discretization errors in solving the ice flow, the massconservation equations and Eqn (2);

6. error in the date of 2012 being the year that these corpses emerged at the surface.

For item 2, an error of the surface in 2012 has significantly more impact on the reconstruction of the trajectory than an error of the surface in 1926, since the starting time of the integration is 2012. Additionally, the DEM for the surface in 1926 is known and was used to initialize our model, such that the accuracy of the model was rendered optimal $( \pm 3$ to $5 \mathrm{~m}$; Bauder and others, 2007). As a consequence, only the error for the surface in 2012 was investigated. Further, errors of the mass-balance model (item 3) affect only the top surface and have a limited effect on the trajectories of deep ice particles. Thus, the effects of such errors are more pronounced when the particle gets close to the surface. For instance, if the melting is overestimated in our model, then the modelled ice particle would reach the glacier surface too soon. However, the particle was close to the surface only during the extreme years of 1926 and 2012. For these years, the errors of surfaces have already been taken into account in item 2, so we dropped item 3 from the sensitivity analysis. Finally, we also dropped the effects of the discretization errors (item 5), since they are likely to be negligible compared with the modelling errors (item 4).

For the other sources, we analyzed the sensitivity of our result by modifying a parameter in the model or the location of $\mathbf{x}_{2012}$ and determining the resulting shift in the upper emergence point of the trajectory. To perform such an analysis, it was convenient to define local frames oriented to the lateral and longitudinal direction of the trajectory. We let $\left[\mathbf{x}^{\mathrm{h}},\left(\mathbf{e}_{\text {lat }}^{\mathrm{h}}, \mathbf{e}_{\text {long }}^{\mathrm{h}}, \mathbf{e}_{z}\right)\right]$ (or $\left[\mathbf{x}^{\mathrm{f}},\left(\mathbf{e}_{\text {lat' }}^{\mathrm{f}}, \mathbf{e}_{\text {long }}^{\mathrm{f}}, \mathbf{e}_{z}\right)\right]$ ) be the local frame at the head (or foot) of the trajectory, such that $\mathbf{x}^{\mathrm{h}}$ (or $\mathbf{x}^{\mathrm{f}}$ ) was the location of the head (or foot), $\mathbf{e}_{\text {long }}^{i}(i \in\{\mathrm{f}, \mathrm{h}\})$ was the projection onto the horizontal plane of the tangent at $\mathbf{x}^{i}$ to the trajectory oriented with the time variable and $\mathbf{e}_{\text {lat }}^{i}$ was horizontal and orthogonal to $\mathbf{e}_{\text {long }}^{i}$. If we perturbed the model parameters by changing $(A, C)$ or the foot of the trajectory, $\mathbf{x}^{\mathrm{f}}$, by

$$
\mathbf{x}_{\delta}^{\mathrm{f}}=\mathbf{x}^{\mathrm{f}}+\delta_{\text {lat }}^{\mathrm{f}} \mathbf{e}_{\text {lat }}^{\mathrm{f}}+\delta_{\text {long }}^{\mathrm{f}} \mathbf{e}_{\text {long }}^{\mathrm{f}}+\delta_{z} \mathbf{e}_{z}
$$

with $\left(\delta_{\text {lat }}, \delta_{\text {long }}, \delta_{z}\right) \in \mathcal{R}^{3}$, then the head of the trajectory, $\mathbf{x}^{\mathrm{h}}$, became

$$
\mathbf{x}_{\delta}^{\mathrm{h}}=\mathbf{x}^{\mathrm{h}}+\delta_{\text {lat }}^{\mathrm{h}} \mathbf{e}_{\text {lat }}^{\mathrm{h}}+\delta_{\text {long }}^{\mathrm{h}} \mathbf{e}_{\text {long }}^{\mathrm{h}}+\delta_{z}^{\mathrm{h}} \mathbf{e}_{z}
$$

with $\left(\delta_{\text {lat }}^{\text {h }}, \delta_{\text {long, }}^{\text {h }}, \delta_{z}^{\text {h }}\right) \in \mathcal{R}^{3}$ (Fig. 4). We defined the distance to the surface (dts) function as:

$$
\mathrm{dts}_{\delta}=s\left(x_{\delta}^{\mathrm{h}}, y_{\delta}^{\mathrm{h}}, t^{\mathrm{h}}\right)-z_{\delta}^{\mathrm{h}},
$$

which provided a more natural indicator than $\delta_{z}^{\text {h }}$ for the vertical deviation. In the following, we estimated the effects of any perturbation on $\left(\delta_{\text {lat }}^{\mathrm{h}}, \delta_{\text {long }}^{\mathrm{h}}, \mathrm{dts} \delta\right)$.

We first quantify the error in the location of $\mathbf{x}_{2012}$. The record was made by the police using a conventional GPS device with an accuracy of $\sim 10 \mathrm{~m}$, and the remains were found roughly within a $10 \mathrm{~m}$ wide square (Police Report, 2012: Polizeirapport, Kanton Wallis, unpublished and confidential). For this reason, we recomputed the trajectories, taking as starting locations four points in the vicinity of $\mathbf{x}_{2012}$ : two $15 \mathrm{~m}$ forward and backward, and two $15 \mathrm{~m}$ to each side (Table 1). As a result, the lateral deviation of the final location of the trajectory never exceeded $57 \mathrm{~m}$ and the longitudinal deviation never exceeded $92 \mathrm{~m}$.

The uncertainties of the surface in 2012 and their impact on the reconstructed trajectory are now evaluated. This surface relies on the DEM of the year 1999 (which is $\pm 1 \mathrm{~m}$ accurate; Bauder and others, 2007), and 13 years of modelling. As a consequence, the uncertainty can be directly evaluated by computing the difference between the elevation of the modelled surface at $\left(x_{2012}, y_{2012}\right)$ and the exact altitude, $Z_{2012}$, which is known. It was found that the surface is $8 \mathrm{~m}$ above $Z_{2012}$ :

$$
s\left(x_{2012}, y_{2012}, 2012\right)-z_{2012}=2438-2430=8 \mathrm{~m} .
$$

To evaluate the consequences of this error on Eqn (3), we recomputed the trajectory by taking $\mathbf{x}_{2012}+\delta_{z} \mathbf{e}_{z}$ with $\delta_{z}=-4,4,8 \mathrm{~m}$ as starting locations (Table 1 ). As a result, the end of the trajectory obtained by starting exactly from the modelled surface $\left(\delta_{z}=8\right)$ deviated significantly, by $33 \mathrm{~m}$ laterally and $260 \mathrm{~m}$ longitudinally, while its distance to surface, $\mathrm{dts}_{\delta}$, was quite high, $47 \mathrm{~m}$. Although it is expected that two particles that are vertically close to each other may have followed very different trajectories and have distant 
Table 1. Sensitivity of the final position of the trajectory, $\mathbf{x}(1926$, $\mathbf{x}_{2012}, 2012$ ), with respect to shifts in model parameters and location of $\mathbf{x}_{2012}$. The input perturbations are listed on the left and the output perturbations on the right

\begin{tabular}{|c|c|c|c|c|c|c|c|}
\hline & & Inputs & & & & Outputs & \\
\hline & $\delta_{\text {lat }}^{\mathrm{f}}$ & $\delta_{\text {long }}^{f}$ & $\delta_{z}^{f}$ & $t_{f}$ & $\delta_{\text {lat }}^{\mathrm{h}}$ & $\delta_{\text {long }}^{\mathrm{h}}$ & $\mathrm{dts}_{\delta}$ \\
\hline$\left(A_{3}, C_{3}\right)$ & 0 & 0 & 0 & 2012 & 0 & 0 & 26 \\
\hline$\left(A_{3}, C_{3}\right)$ & 15 & 0 & 0 & 2012 & 45 & 92 & 33 \\
\hline$\left(A_{3}, C_{3}\right)$ & -15 & 0 & 0 & 2012 & -57 & -52 & 20 \\
\hline$\left(A_{3}, C_{3}\right)$ & 0 & 15 & 0 & 2012 & -5 & 63 & 30 \\
\hline$\left(A_{3}, C_{3}\right)$ & 0 & -15 & 0 & 2012 & 5 & -43 & 23 \\
\hline$\left(A_{3}, C_{3}\right)$ & 0 & 0 & -4 & 2012 & -3 & -68 & 35 \\
\hline$\left(A_{3}, C_{3}\right)$ & 0 & 0 & 4 & 2012 & 7 & 106 & 34 \\
\hline$\left(A_{3}, C_{3}\right)$ & 0 & 0 & 8 & 2012 & 33 & 260 & 47 \\
\hline$\left(A_{1}, c_{1}\right)$ & 0 & 0 & 0 & 2012 & 175 & 684 & 32 \\
\hline$\left(A_{2}, C_{2}\right)$ & 0 & 0 & 0 & 2012 & 126 & 228 & 13 \\
\hline$\left(A_{4}, C_{4}\right)$ & 0 & 0 & 0 & 2012 & 136 & -528 & 4 \\
\hline$\left(A_{5}, C_{5}\right)$ & 0 & 0 & 0 & 2012 & 171 & -554 & 17 \\
\hline$\left(A_{3}, C_{3}\right)$ & & $\mathbf{x}^{\dagger}=\tilde{\mathbf{x}}_{2007}$ & & 2007 & 9 & 92 & 19 \\
\hline$\left(A_{3}, C_{3}\right)$ & & $\mathbf{x}^{\dagger}=\tilde{\mathbf{x}}_{2002}$ & & 2002 & 27 & 47 & 5 \\
\hline$\left(A_{3}, C_{3}\right)$ & & $\mathbf{x}^{f}=\tilde{\mathbf{x}}_{1997}$ & & 1997 & -4 & -250 & 18 \\
\hline$\left(A_{3}, C_{3}\right)$ & & $\mathbf{x}^{\mathbf{f}}=\tilde{\mathbf{x}}_{1992}$ & & 1992 & -23 & -303 & 3 \\
\hline
\end{tabular}

origins, this deviation was raised by a numerical artefact. Indeed, the top surface of the glacier in the volume-of-fluid method is represented by a thin diffusive layer (Jouvet and others, 2008, 2009), which might artificially slow down the particles at the surface. To remove such an artefact, it is necessary to start the integration slightly below the surface. It was found that the trajectories obtained by doing so (with $\delta_{z}=4,0,-4 \mathrm{~m}$ ) are less sensitive to the aforementioned artefact, such that $\delta_{z}= \pm 4 \mathrm{~m}$ can be used as bounds in the sensitivity analysis. As a result, the final locations of the trajectories never deviated more than $7 \mathrm{~m}$ laterally or $106 \mathrm{~m}$ longitudinally, while their distance to surface, $\mathrm{dts}_{\delta}$, remained small.

Since we used the Stokes model, which is the most advanced ice-flow model (Greve and Blatter, 2009), no uncertainty due to mechanical simplifications was introduced. However, the model was isothermal. As a consequence, the main source of error was related to the rate factor, $A$, and the basal sliding, $C$. Extending the work of Jouvet and others (2011), for each $A=A_{i}$ in

$$
\left\{A_{1}=60, A_{2}=80, A_{3}=100, A_{4}=120, A_{5}=150\right\}
$$

we searched for the optimal parameter $C=c_{i}$ that minimizes the difference between modelled and averaged measured surface velocities, and found

$\left\{c_{1}=56900, c_{2}=37000, c_{3}=23300, c_{4}=12500, c_{5}=0\right\}$.

Among the pairs $\left\{\left(A_{i}, C_{i}\right), i=1,2,3,4,5\right\}$, the optimal parameters were $(A, C)=\left(A_{3}, C_{3}\right)$ with a root-mean-square error (RMSE) between measured and simulated velocities of $\sim 19 \mathrm{~m} \mathrm{a}^{-1}$. However, other pairs also proved to be realistic with $\sim 25, \sim 19, \sim 23$ and $\sim 31 \mathrm{~m} \mathrm{a}^{-1} \operatorname{RMSE}$ for $\left(A_{1}, c_{1}\right)$, $\left(A_{2}, C_{2}\right),\left(A_{4}, C_{4}\right)$ and $\left(A_{5}, C_{5}\right)$. These pairs represent two kinds of velocity profile: $\left(A_{1}, C_{1}\right)$ and $\left(A_{2}, C_{2}\right)$ account for more sliding and less ice shearing, while $\left(A_{4}, c_{4}\right)$ and $\left(A_{5}, C_{5}\right)$ account for more ice shearing and less sliding (no sliding for $\left.\left(A_{5}, C_{5}\right)\right)$. Thus, the measured surface velocities do not determine $(A, C)$ uniquely, as they can be reproduced with various ratios of sliding and shearing. Since we know that the

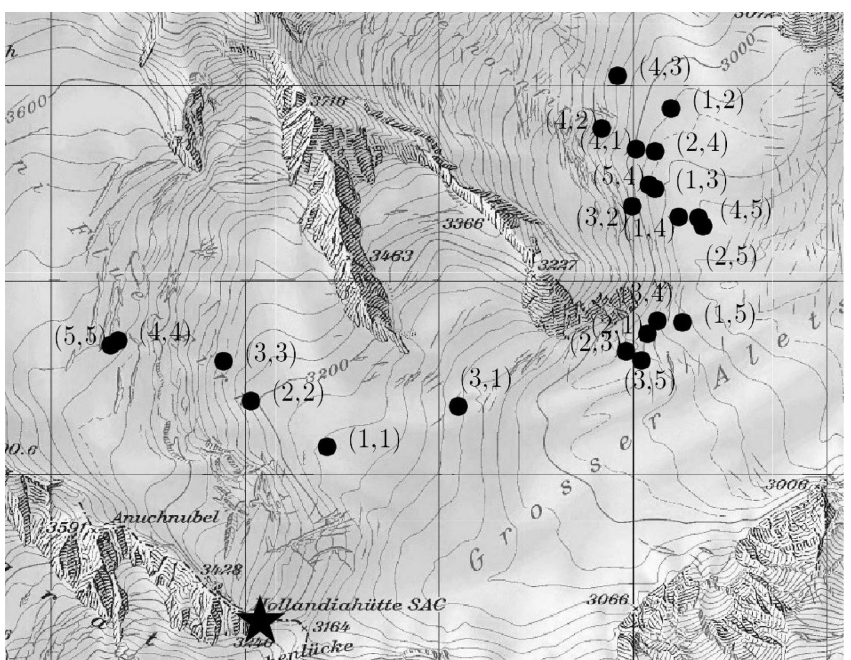

Fig. 5. Aerial view, similar to Figure 2. The black dots labelled $(i, j)$ indicate the horizontal position of the final point of the trajectory obtained with model parameters $\left(A_{i}, c_{j}\right)$ of Table 2.

corpses of the mountaineers that entered the glacier in 1926 went through the location $\mathbf{x}_{2012}$ in 2012 , we can corroborate the choice of $(A, C)$ with these additional data. For all pairs $\left(A_{i}, C_{j}\right)$, the model was run from 1926 to 2012 and the trajectory $\mathbf{x}\left(t, \mathbf{x}_{2012}, 2012\right)$ was integrated backward in time to obtain the distance to the surface, $\mathrm{dts}_{\delta}$ (Table 2), and the final location, $\mathbf{x}\left(1926, \mathbf{x}_{2012}, 2012\right)$ (Fig. 5). Since $\mathbf{x}_{2012}$ might have been above or below the modelled surface in 2012, the integration of the trajectory was not initialized at $\mathbf{x}_{2012}$, but slightly below at its vertical projection on the modelled surface. Table 2 and Figure 5 clearly indicate two categories of parameters. First, the diagonal pairs $\left\{\left(A_{i}, C_{i}\right), i=1, \ldots, 5\right\}$ led to trajectories ending in the same basin (Fig. 5). Importantly, the $\mathrm{dts}_{\delta}$ and the RMSE were simultaneously the smallest for these pairs (Table 2). This shows that the diagonal pairs $\left\{\left(A_{i}, C_{i}\right), i=1, \ldots, 5\right\}$ that were calibrated using velocity measurements, were confirmed by the new data. However, since all $\mathrm{dts}_{\delta}$ were small, this indicator cannot be used to choose between the diagonal pairs. In contrast, all other pairs $\left\{\left(A_{i}, c_{j}\right), i \neq j\right\}$ (except $\left.\left(A_{3}, c_{1}\right)\right)$ led to trajectories ending either in, or at the entrance to, another basin (Fig. 5). Additionally, most of the final positions of trajectories were still deep below the glacier surface, as indicated by the high $\mathrm{dts}_{\delta}$ (Table 2). These results confirm that non-diagonal pairs must be excluded. Interestingly, Figure 5 shows that an

Table 2. Distance to the surface, $\mathrm{dts}_{\delta}$ (left number), and RMSE (right number) between measured and simulated velocity (Jouvet and others, 2011) for different model parameters, $A\left(\mathrm{MPa}^{-3} \mathrm{a}^{-1}\right)$ and $C$ $\left(\mathrm{MPa}^{-3} \mathrm{~m} \mathrm{a}^{-1}\right)$. NC stands for 'not calculated'

\begin{tabular}{lrrrrl}
\hline & $A_{1}$ & $A_{2}$ & \multicolumn{1}{c}{$A_{3}$} & \multicolumn{1}{c}{$A_{4}$} & \multicolumn{1}{c}{$A_{5}$} \\
\hline$C_{1}$ & $\mathbf{3 2 / 2 5}$ & $46 / 32$ & $68 / 54$ & $90 / 78$ & $\mathrm{NC} / 113$ \\
$C_{2}$ & $54 / 34$ & $\mathbf{1 3 / 1 9}$ & $31 / 29$ & $63 / 50$ & $\mathrm{NC} / 83$ \\
$C_{3}$ & $57 / 49$ & $65 / 28$ & $\mathbf{2 6} / \mathbf{1 9}$ & $28 / 31$ & $\mathrm{NC} / 61$ \\
$C_{4}$ & $75 / 65$ & $61 / 45$ & $17 / 28$ & $\mathbf{4} / \mathbf{2 3}$ & $63 / 43$ \\
$C_{5}$ & $32 / 95$ & $86 / 76$ & $84 / 58$ & $111 / 42$ & $\mathbf{1 7} / \mathbf{3 1}$ \\
\hline
\end{tabular}


incorrect parameterization of the ice-flow model changes the result dramatically. Since rate factors $A$ between 80 and $100 \mathrm{MPa}^{-3} \mathrm{a}^{-1}$ are usually recommended in the literature (Hubbard and others, 1998; Gudmundsson, 1999) for comparable mountain glaciers, we exclude the pair $\left(A_{5}, C_{5}\right)$ and restrict our consideration to

$$
(A, c) \in\left\{\left(A_{1}, C_{1}\right),\left(A_{2}, C_{2}\right),\left(A_{3}, C_{3}\right),\left(A_{4}, C_{4}\right)\right\} .
$$

Table 1 shows the deviations of the final location of the trajectory obtained with model parameters $\left(A_{1}, C_{1}\right),\left(A_{2}, C_{2}\right)$ and $\left(A_{4}, C_{4}\right)$. If $\left(A_{1}, C_{1}\right)$ (or $\left.\left(A_{2}, C_{2}\right)\right)$ were chosen instead of $\left(A_{3}, C_{3}\right)$, then the location of the corpses in 1926 would be $\sim 680 \mathrm{~m}$ (or $230 \mathrm{~m}$ ) downstream. Indeed, since no sliding was assumed above $2400 \mathrm{~m}$ a.s.l., reducing $A$ made the ice flow globally slower. In contrast, the parameters $\left(A_{4}, C_{4}\right)$ led to faster flow and to the location of the corpses in $1926 \sim 530 \mathrm{~m}$ upstream. Note that the deviation is mostly longitudinal, since the lateral deviation never exceeds $175 \mathrm{~m}$.

The skeletons were discovered in June immediately after winter snowmelt and there is no evidence that they had reached the surface earlier. Human bodies are usually preserved (by mummification) when confined in ice (Ambach and others, 1992). Since the mountaineers died in March, it is very likely that the bodies were immediately covered by snow and thus remained frozen and intact until they reached the surface. Regarding the time required for the bodies to decompose and the bones to erode, it was established that the corpses were exposed at the surface of the glacier for several seasons. Additionally, the human remains had little chance of being found immediately they came to the surface, since their location, $\mathbf{x}_{2012}$, lay on the west side of the tongue and far from the east-side summer route usually taken by mountaineers. Nevertheless, Aletschgletscher is popular during the summer season and the west side is also visited from time to time. Thus, it seems unlikely that the corpses emerged more than 10 years prior to 2012 (and even more unlikely it could have been 20 years earlier). To explore the effects of this unknown period at the head of the trajectory, we performed several experiments assuming time intervals of 5, 10, 15 and 20 years between the emergence of the corpses at the surface and their discovery. For instance, if the corpses had emerged in year $Y$ instead of 2012, the bodies would very probably be close to

$$
\tilde{\mathbf{x}}_{Y}=\left(x_{Y}, y_{Y}, s\left(\mathbf{x}_{Y}, Y\right)\right),
$$

where $\mathbf{x}_{Y}=\mathbf{x}\left(Y, \mathbf{x}_{2012}, 2012\right)$ is the point of the trajectory in $Y$ (Fig. 2). Taking $Y$ equal to 2007, 2002, 1997 or 1992, we recomputed the trajectory by taking $\left(\tilde{\mathbf{x}}_{1992}, 1992\right),\left(\tilde{\mathbf{x}}_{1997}\right.$, 1997), $\left(\tilde{\mathbf{x}}_{2002}, 2002\right)$ and $\left(\tilde{\mathbf{x}}_{2007}, 2007\right)$ as the foot of the trajectory, integrating backward-in-time over the remaining time period, and checked the deviation of the final location (Table 1). We found that the lateral deviation never exceeded $27 \mathrm{~m}$, while the longitudinal deviation never exceeded $303 \mathrm{~m}$. Note that the distance to the surface, $\mathrm{dts}_{\delta}$, is slight in all cases, so this cannot be used as an indicator to distinguish between assumptions.

Assuming that the bodies of the mountaineers appeared on the surface after 2002, the interval of confidence for $\mathbf{x}_{1926}$ given in Eqn (3) (obtained by totalling all sources of uncertainty) is $[-648,974] \mathrm{m}$ longitudinally and $[-60,247] \mathrm{m}$ laterally. Thus, the area where the corpses were probably buried is a $1622 \mathrm{~m}$ long and $307 \mathrm{~m}$ wide rectangle (Fig. 2), which represents $\sim 2.5 \%$ of the Grosser Aletschfirn basin area and $\sim 0.6 \%$ of the entire Aletschgletscher area.

\section{PROBABLE CAUSES OF DEATH}

Based on the uncertainty range of the immersion location, three causes of death are conceivable: (1) a fall into a crevasse, since a highly crevassed zone can be seen in the upstream area of the uncertainty rectangle of Figure 2; (2) avalanche burial, since the surface topography slope immediately above the likely trajectory head is $>30^{\circ}$; and (3) exhaustion/freezing to death. Cause (1) is improbable, because three people falling into a crevasse at the same time is virtually impossible. Cause (2) is also extremely unlikely, because in such a case the bodies would have been spread out over a large area, which is not compatible with the small area in which the remains were found. Therefore we conclude that (3) is the most probable cause of death in the case of the three brothers. Additionally, we note that their last position was not on the path joining the refuge to Konkordiaplatz (where they presumably were coming from), but $\sim 1 \mathrm{~km}$ to the north of the refuge (Fig. 2). This supports the theory that the victims became disoriented due to a lack of reference points in conditions of poor visibility. What happened to the fourth group member remains a mystery. Since no trace of him was found in the remains, he probably separated from the group and died elsewhere.

\section{CONCLUSIONS AND PERSPECTIVES}

Using the model results published by Jouvet and others (2011) and the location where the human remains were found in 2012, we reconstructed the trajectory of the corpses of three brothers who disappeared in 1926 on Aletschgletscher. In particular, the position of their immersion into the glacier - where they probably died - could be determined with great confidence: the area is a $\sim 1600 \mathrm{~m}$ long and $\sim 300 \mathrm{~m}$ wide rectangle, which represents only $\sim 0.6 \%$ of the entire Aletschgletscher area. In addition, the resulting trajectory offers a new and reliable validation of the model presented by Jouvet and others (2011). Indeed, the elevation of the obtained submergence point of the computed trajectory in 1926 is only $26 \mathrm{~m}$ beneath the surface. This small discrepancy attests to the ability of the model to reproduce reality. In contrast to local measurements normally used for model verification purposes, the distance to the surface is global in time and space as an indicator of the model quality, since it accounts for a substantial part of the glacier and a long modelling period. Finally, we have shown that it was crucial to accurately calibrate the ice-flow parameters. As illustrated in Figure 5, an incorrect parameterization changes the immersion location from one basin to another, since a bifurcation of ice flows occurs downstream. Our findings proved to be useful in a $\sim 100$ year old investigation. Corroborated with historical facts, our estimate of the location where the brothers died contributes to a better understanding of what might have caused their deaths. Considering all possible causes, we conclude that the loss of all points of reference produced by severe weather conditions very likely led to the death of the mountaineers by exposure.

In this paper, we have reconstructed the trajectory by integrating backward in time a time-dependent velocity field, starting from the known emergence point of the human remains. It would be straightforward to begin with the head and to predict the trajectory by integrating forward-in-time. This would open the method to another application: to predict when and where the bodies of other 
mountaineers or certain objects will reappear at the surface, when the location and the date of disappearance are known. For instance, the method could also be used to determine the trajectory of the Dakota aircraft of the US Army that crash-landed on the Gauligletscher, Bernese Alps, Switzerland, in November 1946 and is expected to emerge in the coming decades on the top surface of the glacier tongue. In view of the current global warming situation, bodies and objects submerged within Alpine glaciers can be expected to emerge from the ice faster than originally anticipated. A method for establishing the position of various bodies in a glacier, with an estimated place and time of reappearance, would be helpful for identification purposes, and is of immediate interest to the police in charge of such investigations.

\section{ACKNOWLEDGEMENTS}

We are grateful to the Lötschentaler Museum, Kippel, and U. Mosimann of the Swiss Alpine Club for providing us with detailed information about the disappearance and the discovery of the mountaineers. The model and the cfsFlow software used to simulate the evolution of Aletschgletscher were developed at the Ecole Polytechnique Fédérale de Lausanne (EPFL), Switzerland, under the supervision of J. Rappaz and M. Picasso. G.J. was supported by the Deutsche Forschungsgemeinschaft (project KL 1806 5-1). We thank M. Huss (University of Fribourg) and $\mathrm{H}$. Blatter (ETH Zürich) for comments on the manuscript. Other constructive comments by Alexander $\mathrm{H}$. Jarosch and an anonymous referee contributed to improving the manuscript. We also thank S. Braun-Clarke and A.S.J.S. Mey for proofreading the English.

\section{REFERENCES}

Ambach W, Ambach E, Tributsch W, Henn R and Unterdorfer H (1992) Corpses released from glacier ice: glaciological and forensic aspects. J. Wilderness Med., 3(4), 372-376 (doi: 10.1580/0953-9859-3.4.372)

Aschwanden A and Blatter H (2005) Meltwater production due to strain heating in Storglaciären, Sweden. J. Geophys. Res., 110(F4), F04024 (doi: 10.1029/2005JF000328)

Bauder A, Funk M and Huss M (2007) Ice-volume changes of selected glaciers in the Swiss Alps since the end of the 19th century. Ann. Glaciol., 46, 145-149 (doi: 10.3189/ 172756407782871701)

Durand G and 8 others (2007) Change in ice rheology during climate variations - implications for ice flow modelling and dating of the EPICA Dome C core. Climate Past, 3(1), 155-167 (doi: 10.5194/cp-3-155-2007)
Greve R and Blatter H (2009) Dynamics of ice sheets and glaciers. Springer, Dordrecht

Gudmundsson GH (1999) A three-dimensional numerical model of the confluence area of Unteraargletscher, Bernese Alps, Switzerland. J. Glaciol., 45(150), 219-230 (doi: 10.3189/ 002214399793377086)

Hubbard A, Blatter H, Nienow P, Mair D and Hubbard B (1998) Comparison of a three-dimensional model for glacier flow with field data from Haut Glacier d'Arolla, Switzerland. J. Glaciol., 44(147), 368-378

Huss M and Bauder A (2009) 20th-century climate change inferred from four long-term point observations of seasonal mass balance. Ann. Glaciol., 50(50), 207-214 (doi: 10.3189/ 172756409787769645)

Huss M, Bauder A, Funk M and Hock R (2008) Determination of the seasonal mass balance of four Alpine glaciers since 1865. J. Geophys. Res., 113(F1), F01015 (doi: 10.1029/2007JF000803)

Jouvet G, Picasso M, Rappaz J and Blatter H (2008) A new algorithm to simulate the dynamics of a glacier: theory and applications. J. Glaciol., 54(188), 801-811 (doi: 10.3189/ 002214308787780049)

Jouvet G, Huss M, Blatter H, Picasso M and Rappaz J (2009) Numerical simulation of Rhonegletscher from 1874 to 2100. J. Comput. Phys., 228(17), 6426-6439 (doi: 10.1016/j.jcp.2009. 05.033)

Jouvet G, Huss M, Funk $M$ and Blatter $H$ (2011) Modelling the retreat of Grosser Aletschgletscher, Switzerland, in a changing climate. J. Glaciol., 57(206), 1033-1045 (doi: 10.3189/ 002214311798843359)

Krämer M, Lehner P and Zink P (1988) Über zwei Gletscherleichen mit 'Eiszeiten' von 70 und 400 Jahren. In Bauer G ed. Gerichtsmedizin. Festschrift für Wilhelm Holczabek. Franz Deuticke, Wien, 5-8

Loreille OM and 9 others (2010) Integrated DNA and fingerprint analyses in the identification of 60-year-old mummified human remains discovered in an Alaskan glacier. J. Forensic Sci., 55(3), 813-818 (doi: 10.1111/j.1556-4029.2010.01356.x)

Martín C, Gudmundsson GH, Pritchard HD and Gagliardini O (2009) On the effects of anisotropic rheology on ice flow, internal structure, and the age-depth relationship at ice divides. J. Geophys. Res., 114(F4), F04001 (doi: 10.1029/2008JF001204)

Mügge B, Savvin A, Calov R and Greve R (1999) Numerical age computation of the Antarctic ice sheet for dating deep ice cores. In Hutter K, Wang $\mathrm{Y}$ and Beer $\mathrm{H}$ eds. Advances in cold-region thermal engineering and sciences: technological, environmental, and climatological impact. Springer, Berlin, 307-318

Rossberg RR (1983) Die Jungfrau-Region und ihre Bahnen. Hallwag, Bern

Stolle DFE and Killeavy MS (1986) Determination of particle paths using the finite-element method. J. Glaciol., 32(111), 219-223

Zwinger T, Greve R, Gagliardini O, Shiraiwa T and Lyly M (2007) A full Stokes-flow thermo-mechanical model for firn and ice applied to the Gorshkov crater glacier, Kamchatka. Ann. Glaciol., 45, 29-37 (doi: 10.3189/172756407782282543)

MS received 1 August 2013 and accepted in revised form 14 November 2013 